\title{
Brownout: another threat to ICU physicians and nurses
}

Xavier Valette ${ }^{*}$ (I)

(c) 2018 Springer-Verlag GmbH Germany, part of Springer Nature and ESICM

\section{Dear Editor,}

The interesting article by E. Kompanje underlines the risk of burnout, boreout and compassion fatigue in ICU physicians and nurses by describing real-life situations of suffering at work [1]. However, brownout is another occupational pathology that threatens healthcare providers [2].

Burnout, boreout and compassion fatigue are exhaustion syndromes, one by work and emotional involvement overload, the second by boredom in relation with idleness, and the last one by saturation of the altruistic relationship of the caregiver with the patient or his relatives [1]. In contrast, brownout is related to the impairment of the philosophical conception of the purpose of work [2]. In ICU, applying invasive treatments to a frail population like the oldest patients, and patients with many comorbidities or suffering from pathologies with poor functional or vital outcomes like stroke or metastatic cancer, can lead the caregiver to question the finality of his practice. Incomprehension about his work and his place in society may appear. Thus, the healthcare provider loses their goals and self-esteem, and becomes unmotivated, disinvested, tired and irritable. These symptoms should not be confused with depression in which the mood changes have no triggering element. Likewise, brownout should not be confused with burnout because it is the loss of meaning of care for the caregiver that is responsible for the symptoms not overwork.

The ICU physician depicted in the article has symptoms of brownout [1,2]. In addition to the individual approach reported by Kompanje, an ICU-team-based strategy seems necessary to give consistency and meaning to critical care by analyzing, and consequently modifying, the practices in the ICU.

Compliance with ethical standards

\section{Conflicts of interest}

The author state that there is no conflict of interest.

Published online: 23 May 2018

\section{References}

1. Kompanje EJO (2018) Burnout, boreout and compassion fatigue on the ICU: it is not about work stress, but about lack of existential significance and professional performance. Intensive Care Med. https://doi. org/10.1007/s00134-018-5083-2

2. Alvesson Mats, Spicer André (2016) The stupidity paradox: the power and pitfalls of functional stupidity at work. Profile, London 